\title{
Multiple Sclerosis Related Bowel Dysfunction: Pathophysiology, Clinical Manifestation and Management
}

Kumaran Thiruppathy ${ }^{1,2^{*}}$, Giuseppe Preziosi ${ }^{1,2}$, Adeel Bajwa $^{1}$, Prashant Sharma $^{2}$, Marasol Cerdeira ${ }^{2}$, Shanthan Ganesh ${ }^{2}$ and Anton Emmanuel ${ }^{1}$

${ }^{1}$ Department of Gastroenterology, University college Hospital London, London, England, UK

${ }^{2}$ Academic Department of Surgery, The Queen Elizabeth Hospital, Adelaide, Australia

"Corresponding author: Kumaran Thiruppathy, Research and Colorectal Fellow, Department of Surgery, Academic Unit of Colorectal Surgery, The Queen Elizabeth Hospital, Woodville Road, South Woodville SA 5011, Australia, Tel: 82226000; Email: kum.nhs@gmail.com

Received date: Mar 24, 2014, Accepted date: Dec 09, 2014, Published date: Dec 15, 2014

Copyright: @ 2014 Thiruppathy K, et al. This is an open-access article distributed under the terms of the Creative Commons Attribution License, which permits unrestricted use, distribution, and reproduction in any medium, provided the original author and source are credited.

\begin{abstract}
Bowel dysfunction amongst multiple sclerosis (MS) patients often manifests as faecal incontinence (FI), constipation, or a combination of the two. Its pathophysiology is poorly understood and can be multifactorial. Anorectal physiology provides an objective assessment of lower bowel functions and is increasingly being used in clinical practice. Due to the varied and fluctuant nature of the symptoms, these patients can be a management challenge. This review aims to give an overview of the pathophysiology, clinical manifestations and the principles of management of multiple sclerosis patients with bowel dysfunction.
\end{abstract}

Keywords: Anorectal physiology; Multiple sclerosis; Faecal incontinence; Constipation; Bowel dysfunction

\section{Introduction}

Bowel dysfunction is common amongst patients with neurological diseases. It is a very distressing problem, physically, mentally and socially. In the general population, the incidence of faecal incontinence and constipation is estimated at $2-4 \%$ and $2-26 \%$ respectively $[1,2]$. Amongst patients with multiple sclerosis (MS), faecal incontinence affects $24 \%$ to $66 \%$ and constipation is reported at 24 to $40 \%$ [3-6]. These symptoms can be distressing and can have a significant impact on the quality of life of patients.

For a variety of reasons, faecal incontinence and constipation are under recognised and undertreated problem in the community. Patients tend to under report the problem, because of the social stigma associated with it, whilst amongst healthcare practitioners there is a lack of active screening, urgency in investigating and referring the symptoms on. The problem however is very significant and amongst MS patients, these symptoms are ranked as the third commonest cause for inability to work [7].

The pathophysiology of bowel dysfunction amongst MS patients is poorly understood. Currently, the aetiology is thought to be multifactorial (Figure 1 and 2). Factors such as the relapsing and remitting nature of the disease, duration and the severity can all affect the patients symptom load [8-12]. These symptoms are further influenced by variables such as psychological dysfunction, immobility and pharmacological therapies $[9,13]$. Drugs such as opiates, anticholinergics and pain modulators may predispose to constipation or over flow incontinence, whilst laxatives used to treat constipation may predispose to faecal incontinence especially in patients with limited motor function or having rectal sensory impairment.

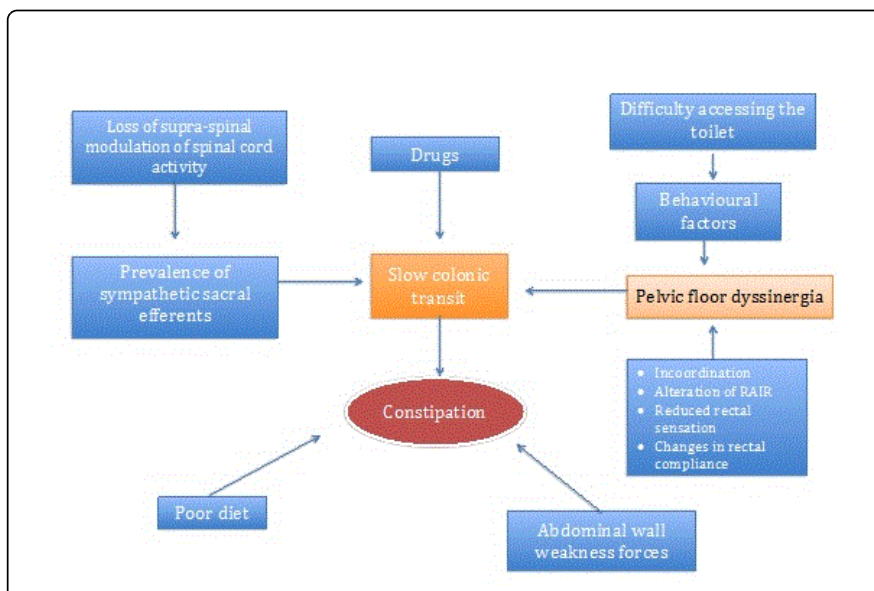

Figure 1: Potential mechanisms underlying constipation in Multiple Sclerosis patients

Different patterns of abnormality of anorectal physiology have been demonstrated in MS patients with bowel dysfunction [14]. Some anorectal physiology studies have demonstrated that neurological impact of MS can be gut specific, and may be linked to or independent of both severity and duration of the disease in the brain $[13,14]$.

\section{Physiology of the anorectum}

Normal bowel function is dependent on the function of the colon and rectum. These account for about $90 \%$ of gut transit time. Bowel evacuation and continence is dependent on the functional and structural integrity of the colon but in particular the anorectum. 


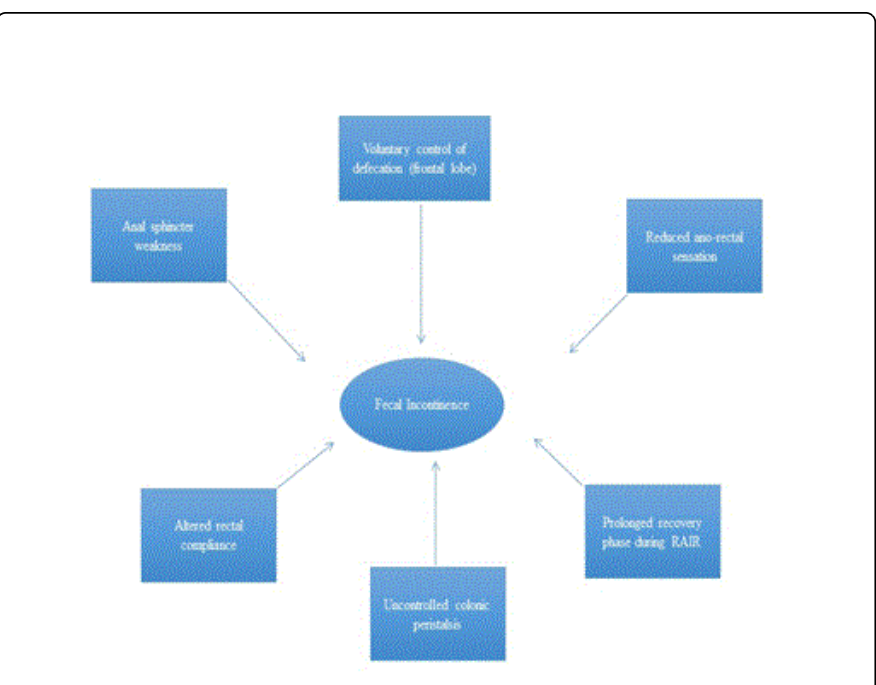

Figure 2: Mechanisms underlying Faecal Incontinence in patients with Multiple Sclerosis.

Central to this mechanism are the colo-colonic and anorectal reflexes that detect rectal content and volume, facilitates storage and subsequent evacuation. Other than the external anal sphincter, the colon and anorectum receive no somatic innervation. Colonic and anorectal function are controlled by a series of reflexes through the intrinsic (enteric) nervous system, and is modulated by the autonomic nervous system. This extrinsic influence is responsible for both conscious and sub-conscious bowel function.

The autonomic system is responsible for the transmission of sensation from the anorectum. The transmission of noxious sensation is through the lumbar (sympathetic) nerves $[15,16]$. Sacral afferent (parasympathetic) fibres are thought to be primarily responsible for the conduction of visceral non-noxious sensation from the anorectum [16-19]. These sacral afferent fibres then travel via the spinothalamic tract and other ascending pathways to higher centres. Parasympathetic stimulation accelerates bowel transit whilst sympathetic stimulation slows down bowel transit [20-22]. Autonomic innervation can also alter internal anal sphincter function and rectal compliance [23].

One proposed mechanism for MS to affect bowel function is that sclerotic plaques directly or indirectly affect the central descending autonomic pathways, affecting these reflexes [24]. Injuries to these pathways are thought to be why urinary and colorectal dysfunction coexists [25].

Anorectal physiology studies in MS patients with constipation has been associated with a decrease in rectal compliance, reduced anal and rectal sensation which may reflect a reduced awareness to rectal content and a loss of normal desire to defaecate [26,27]. Other authors have described an obstructive defaecatory picture with the failure of the sphincters to relax -anismus [20]. FI has also been associated with reduced rectal and anal sensation, abnormalities of the recto anal inhibitory reflex, reduced anal sphincter resting tone and squeeze pressures [20].

\section{Management of bowel dysfunction in Multiple sclerosis}

There are no formal clinical or evidence based management algorithm outlined for the treatment of bowel symptoms in multiple sclerosis. Treatment is usually empirical with a stepwise approach [28] (Figure 3). All patients require a formal and thorough assessment. A careful history with regard to type of symptoms, symptom load, and type of incontinence is essential. The history should also include past anorectal procedures, obstetric history, and past medical history of colorectal problems. A review of medication may also reveal important clues as to the aetiology of the problem. Multiple sclerosis patients have the same risks of other bowel pathology as those without multiple sclerosis, therefore symptoms should not just be attributed to MS, but should be investigated thoroughly. Symptom load can be quantified using one of a range of validated symptoms scores. Commonly used scoring systems for incontinence includes the Wexner incontinence or St Marks incontinence questionnaire, whilst the Wexner constipation questionnaire in commonly used to assess constipation.

A careful and thorough clinical examination should be performed in all patients. A digital rectal examination is mandatory, as it provides vital information about anal sphincter tone, and squeeze pressures, as well as the volume and consistency of stool in the rectum.

All patients with incontinence should have basic investigations including a blood count, electrolytes and inflammatory markers performed. Stool cultures should also be performed to exclude a microbiological cause of symptoms when symptoms dictate. Colonic assessment with colonoscopy or virtual colonoscopy or equivalent investigation should be performed in all patients.

After these investigations, there are a variety of colonic and anorectal tests to assess the physiological function of the anorectum. This includes anorectal physiology, endoanal ultrasound, defaecating proctograms, and colonic transit studies. These tests are complex and generally performed at specialist centres as they often require a specialist to perform and interpret them.

The specifics on how to perform and interpret these tests is beyond the scope of or review. Generally speaking, anorectal physiology testing allows for assessment of anal sphincter function, rectal sensation and compliance. Anorectal innervation can also now be assessed with physiology testing. Endoanal ultrasound allows for detection of sphincter injuries. Transit studies can assess for slow transit constipation. Defaecograms are performed to diagnose and evaluate pathology leading to evacuation difficulties, such as prolapse and rectocoeles.

When treating MS patients the treatment has to be tailored to the type of symptoms the patient has; constipation versus faecal incontinence or a mixed picture, and also to the symptom load [20]. It is vitally important to ascertain a realistic expectation from the patient. By having a realistic tailored management plan along with patient education, compliance to treatment is more likely.

Simple measure such as manipulation of life style should be implemented in the first instance [29]:

Rationalizing poly-pharmacy and simplifying drug regimes to minimise constipating agents or overuse of laxatives promoting incontinence.

Rationalizing fibre intake to prevent constipation while avoiding abdominal bloating

Optimizing fluid intake to more than 1.5 litres per day 
Citation: Thiruppathy K, Preziosi G, Bajwa A, Sharma P, Cerdeira M, et al. (2014) Multiple Sclerosis Related Bowel Dysfunction: Pathophysiology, Clinical Manifestation and Management. J Neurol Neurophysiol 5: 255. doi:10.4172/2155-9562.1000255

Page 3 of 5

Avoiding excess caffeine, sorbitol or artificial sweeteners which can promote loose stools and soiling

Bowel regimes with an attempting to coordinated defaecation post prandially to optimize the gastro-colic response, and colonic aboral propulsion thus aiding evacuation.
In our clinical experience these simple measures can be very effective in controlling symptoms in those with a low symptom burden.

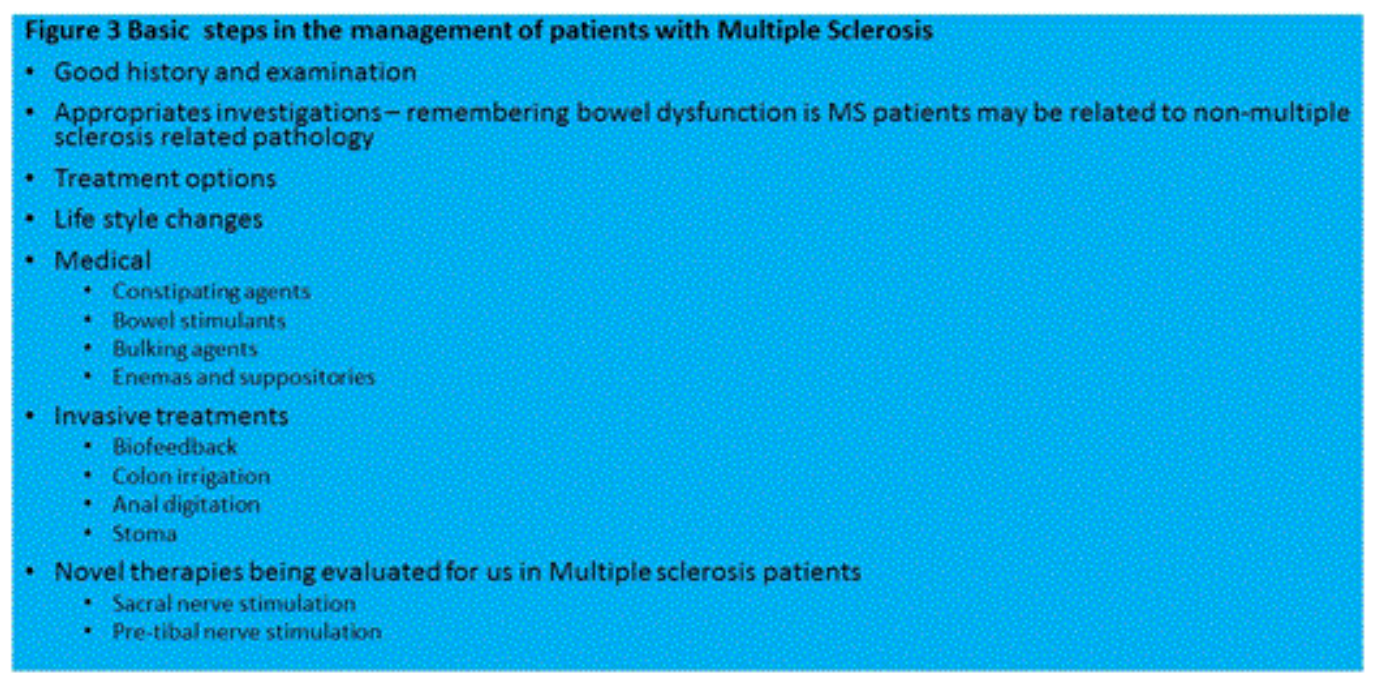

Figure 3: Basic steps in the management of patients with Multiple sclerosis

If simple measures fail then the use of pharmacological agents can be effective. These can be laxatives in the form of stool softeners, motility agents or a combination of both to treat constipation [13]. There are multiple laxatives on the market and each has their own array of side effects (abdominal bloating, cramping pain, loose motions etc). In those with severe disease with constipation, rectal digitation may be sufficient to evoke a defaecation reflex, but if this fails the use of suppositories and enemas may be effective.

Passive or urge FI, even to small volumes can be devastating to patients. Severe constipation leading to overflow incontinence or seepage is a cause for FI and this group of patients would benefit from regular effective evacuation through the use of laxatives, suppositories or enemas. For those with regular loose motions and frequency the judicious use of constipating agent such as loperamide in the first instance, or codeine may be of benefit. The latter is associated with systemic side effects and should ideally be used as second line.

Whilst the use of bulking agents such as fibrogel may be effective in treating seepage of small amounts of liquid stool, may aid effective evacuation and reduce post defaecatory soiling it can be associated with bloating, flatulence and abdominal cramping. Anal plugs are useful in the management of some patients preventing faecal and flatulence incontinence.

\section{Interventions}

Biofeedback is proving to be an effective tool in the treatment of both constipation and incontinence in selected cases [30]. It is especially effective in those with limited degree of disability [14]. It can be used to retrain patients to coordinate pelvic floor function, educate patients and through a multi-modal approach improve symptoms which can be demonstrated through physiology and functional outcome. However this process is very clinician and patient dependent. The initiation of the anorectal evacuation reflex on anal digitation can be employed successfully in selected patients with severe bowel dysfunction with good results.

The role of sacral nerve stimulators in the management of both urinary and faecal incontinence is proving to be effective in the short and long term, however its role in constipation is not so clear. To-date the use has been largely restricted to patients without neurological disease. More recent studies in patients with neurological disease has shown it to be effective [31]. In selected patients with multiple sclerosis (i.e, with less severe, stable disease and low symptom load) there may be a role for this technique. Less invasive procedures like tibial nerve stimulator have been shown to be effective in managing bowel function in patients with idiopathic incontinence and are being assessed for their use in improving bowel function in multiple sclerosis patients $[32,33]$.

Anterograde and retrograde irrigation of the colon can be useful in the management of bowel dysfunction in patient's refractory to conservative or medical management. Anterograde techniques allow for effective emptying of stool from the colon. There are various options available, such as a surgical appendicostomy, a radiologically placed Chait tube, caecostomy etc. The less invasive technique is the retrograde colonic irrigation. A transanal irrigation apparatus is used to irrigate and empty out the rectum and left side of the colon with great effect [34]. In the past the equipment was uncomfortable and 
cumbersome, however newer techniques like the Peristeen have made it easier to use with great effect [34].

The formation of a stoma can be a very effective and simple tool in managing bowel dysfunction. It is effective in those with a severe symptom load who may be refractory to medical treatment, or in whom managing normal bowel function is very difficult i.e. limited physical ability [35]. Surgically stoma formation is generally not difficult, but is dependent on patient factors. Advances in stoma appliances are able to overcome common problems, and the formation of a stoma can give patients independence and control over their own lives. Because of social stigma and negative perceptions, there is an understandable reluctance on the part of patients to choose this option. However, once all medical options are exhausted, and in those patients who choose to proceed with a stoma, most are happy with the results.

\section{Conclusion}

Bowel symptoms in patients with MS can be socially and functionally restricting and difficult to manage. A thorough evaluation is required on all patients. Realistic goals should be agreed on. There should be logical stepwise management plan. Referral to specialist centers will aid investigations and management. Ongoing research into this field will allow us to be to gain a better understanding of the pathophysiology and tailor treatment appropriately to the patient.

\section{References}

1. Rao SS (2004) Pathophysiology of adult fecal incontinence. Gastroenterology 126: S14-22.

2. Santos VL, Domansky Rde C, Hanate C, Matos DS, Benvenuto CV, et al. (2014) Self-reported fecal incontinence in a community-dwelling, urban population in southern Brazil. J Wound Ostomy Continence Nurs 41: 77-83.

3. Miller H, Simpson CA, Yeates WK (1965) Bladder dysfunction in Multiple Sclerosis. Br Med J 1: 1265-1269.

4. Hinds JP, Wald A (1989) Colonic and anorectal dysfunction associated with multiple sclerosis. Am J Gastroenterol 84: 587-595.

5. Nordenbo AM, Andersen JR, Andersen JT (1996) Disturbances of anorectal function in multiple sclerosis. J Neurol 243: 445-451.

6. Bakke A, Myhr KM, Grønning M, Nyland H (1996) Bladder, bowel and sexual dysfunction in patients with multiple sclerosis--a cohort study. Scand J Urol Nephrol Suppl 179: 61-66.

7. Bauer HJ, Firnhaber W, Winkler W (1965) Prognostic criteria in Multiple Sclerosis. Ann N Y Acad Sci 122: 542-551.

8. Munteis E, Andreu M, Téllez MJ, Mon D, Ois A, et al. (2006) Anorectal dysfunction in multiple sclerosis. Mult Scler 12: 215-218.

9. Wiesel PH, Norton C, Glickman S, Kamm MA (2001) Pathophysiology and management of bowel dysfunction in multiple sclerosis. Eur Gastroenterol Hepatol 13: 441-448.

10. Glick ME, Meshkinpour H, Haldeman S, Bhatia NN, Bradley WE (1982) Colonic dysfunction in multiple sclerosis. Gastroenterology 83: 1002-1007.

11. Glickman S, Kamm MA (1996) Bowel dysfunction in spinal-cord-injury patients. Lancet 347: 1651-1653.

12. Krogh K, Nielsen J, Djurhuus JC, Mosdal C, Sabroe S, et al. (1997) Colorectal function in patients with spinal cord lesions. Dis Colon Rectum 40: 1233-1239.

13. Coggrave M, Norton C, Cody JD (2014). Management of faecal incontinence and constipation in adults with central neurological diseases. Cochrane Database Syst Rev 1: CD002115.
14. Munteis E, Andreu M, Martinez-Rodriguez J, Ois A, Bory F, et al. (2008) Manometric correlations of anorectal dysfunction and biofeedback outcome in patients with multiple sclerosis. Mult Scler 14: 237-242.

15. Gebhart GF (2000) Pathobiology of visceral pain: molecular mechanisms and therapeutic implications IV. Visceral afferent contributions to the pathobiology of visceral pain. Am J Physiol Gastrointest Liver Physiol 278: G834-838.

16. MacDonagh R, Sun WM, Thomas DG, Smallwood R, Read NW (1992) Anorectal function in patients with complete supraconal spinal cord lesions. Gut 33: 1532-1538.

17. Joshi SK, Gebhart GF (2000) Visceral pain. Curr Rev Pain 4: 499-506.

18. Chung EA, Emmanuel AV (2006) Gastrointestinal symptoms related to autonomic dysfunction following spinal cord injury. Prog Brain Res 152: 317-333.

19. Goligher JC, Hughes ES (1951) Sensibility of the rectum and colon. Its rôle in the mechanism of anal continence. Lancet 1: 543-547.

20. Thiruppathy K, Roy A, Preziosi G, Pannicker J, Emmanuel A (2012) Morphological abnormalities of the recto-anal inhibitory reflex reflects symptom pattern in neurogenic bowel. Dig Dis Sci 57: 1908-1914.

21. Emmanuel AV, Chung EA, Kamm MA, Middleton F (2009) Relationship between gut-specific autonomic testing and bowel dysfunction in spinal cord injury patients. Spinal Cord 47: 623-627.

22. Knowles CH, Scott SM, Lunniss PJ (2001) Slow transit constipation: a disorder of pelvic autonomic nerves? Dig Dis Sci 46: 389-401.

23. Murray CD, Flynn J, Ratcliffe L, Jacyna MR, Kamm MA, et al. (2004) Effect of acute physical and psychological stress on gut autonomic innervation in irritable bowel syndrome. Gastroenterology 127: 1695-1703.

24. Haensch CA, Jörg J (2006) Autonomic dysfunction in multiple sclerosis. J Neurol 253 Suppl 1: I3-9.

25. Preziosi G, Raptis DA, Raeburn A, Thiruppathy K, Panicker J, et al. (2013) Gut dysfunction in patients with multiple sclerosis and the role of spinal cord involvement in the disease. Eur J Gastroenterol Hepatol 25: 1044-1050.

26. Preziosi G, Raptis DA, Raeburn A, Panicker J, Emmanuel A (2014) Autonomic rectal dysfunction in patients with multiple sclerosis and bowel symptoms is secondary to spinal cord disease. Dis Colon Rectum 57: 514-521.

27. Gladman MA, Lunniss PJ, Scott SM, Swash M (2006) Rectal hyposensitivity. Am J Gastroenterol 101: 1140-1151.

28. Preziosi G, Emmanuel A (2009) Neurogenic bowel dysfunction: pathophysiology, clinical manifestations and treatment. Expert Rev Gastroenterol Hepatol 3: 417-423.

29. Preziosi G, Emmanuel A (2009) Neurogenic bowel dysfunction: pathophysiology, clinical manifestations and treatment. Expert Rev Gastroenterol Hepatol 3: 417-423.

30. Preziosi G, Raptis DA, Storrie J, Raeburn A, Fowler CJ, et al. (2011) Bowel biofeedback treatment in patients with multiple sclerosis and bowel symptoms. Dis Colon Rectum 54: 1114-1121.

31. Vallès M, Rodríguez A, Borau A, Mearin F (2009) Effect of sacral anterior root stimulator on bowel dysfunction in patients with spinal cord injury. Dis Colon Rectum 52: 986-992.

32. de SM, Raibaut P, Gallien P, Even-Schneider A, Denys P, Bonniaud V et al. (2011) Transcutaneous posterior tibial nerve stimulation for treatment of the overactive bladder syndrome in multiple sclerosis: results of a multicenter prospective study. Neurourol Urodyn 30: 306-311.

33. George AT, Kalmar K, Sala S, Kopanakis K, Panarese A, et al. (2013) Randomized controlled trial of percutaneous versus transcutaneous posterior tibial nerve stimulation in faecal incontinence. $\mathrm{Br} \mathrm{J}$ Surg 100: 330-338.

34. Preziosi G, Gosling J, Raeburn A, Storrie J, Panicker J, et al. (2012) Transanal irrigation for bowel symptoms in patients with multiple sclerosis. Dis Colon Rectum 55: 1066-1073. 
Citation: Thiruppathy K, Preziosi G, Bajwa A, Sharma P, Cerdeira M, et al. (2014) Multiple Sclerosis Related Bowel Dysfunction: Pathophysiology, Clinical Manifestation and Management. J Neurol Neurophysiol 5: 255. doi:10.4172/2155-9562.1000255

35. Coggrave MJ, Ingram RM, Gardner BP, Norton CS (2012) The impact of stoma for bowel management after spinal cord injury. Spinal Cord 50: 848-852. 